\title{
BMJ Open School-based behaviour change intervention to increase physical activity levels among children: a feasibility cluster non-randomised controlled trial in Yangzhou, China
}

Haiquan Wang (D) , ${ }^{1,2}$ Holly Blake, ${ }^{3,4}$ Kaushik Chattopadhyay (D) 1,2

To cite: Wang $\mathrm{H}$, Blake $\mathrm{H}$, Chattopadhyay K. Schoolbased behaviour change intervention to increase physical activity levels among children: a feasibility cluster non-randomised controlled trial in Yangzhou, China. BMJ Open 2021;11:e052659. doi:10.1136/ bmjopen-2021-052659

- Prepublication history and additional supplemental material for this paper are available online. To view these files, please visit the journal online (http://dx.doi.org/10.1136/ bmjopen-2021-052659).

Received 28 April 2021 Accepted 04 October 2021

D) Check for updates

(c) Author(s) (or their employer(s)) 2021. Re-use permitted under CC BY-NC. No commercial re-use. See rights and permissions. Published by BMJ.

For numbered affiliations see end of article.

\section{Correspondence to}

Mr Haiquan Wang;

Haiquan.Wang@nottingham. ac.uk

\section{ABSTRACT}

Objectives Children in China have low levels of physical activity. We developed a school-based behaviour change intervention to increase their physical activity levels. The study aimed to determine the feasibility of undertaking a cluster randomised controlled trial (RCT) in the future. This future cluster RCT will evaluate the effectiveness of the intervention.

Design Feasibility cluster non-RCT design.

Setting Two public schools (one intervention and one control) in Yangzhou, China.

Participants Children aged 10-12 years and their parents.

Intervention The 16-week school-based behaviour change intervention to increase physical activity levels consisted of three components (a) health education (physical education), (b) family involvement and (c) school environment support.

Outcomes measures We estimated important parameters that are needed to design the future cluster RCT, such as SD of the primary outcome (ie, 7-day steps in children), intracluster correlation coefficient (ICC), recruitment of child-parent dyads, follow-up of children, completion of and time needed for data collection among children and intervention attendance.

Results Sixty-four children and their parents participated in the study (32 per study group). The SD of the primary outcome was 34519 steps. The ICC was 0.03 . The recruitment and follow-up rates were $100 \%$. The completion of data collection was $100 \%$ (except for the 7-day steps at baseline-one child lost the step log in the intervention group and two children lost their pedometer in the control group). The time needed to complete the self-reported questionnaire by children was around 15 min per study group, and the measurement of their anthropometric parameters took around 40 min per study group. The intervention attendance was $100 \%$.

Conclusions Based on the promising recruitment, followup, completion of and time needed for data collection and intervention attendance, it would be feasible to undertake the future cluster RCT in China.

Trial registration number ChiCTR1900026865.

\section{STRENGTHS AND LIMITATIONS OF THIS STUDY}

$\Rightarrow$ The study provided the estimates of many important parameters needed to design the future cluster randomised controlled trial.

$\Rightarrow$ The study indicated an improvement in children's self-efficacy, enjoyment and social support for physical activity through a physical activity intervention.

$\Rightarrow$ It was difficult to blind participants and those delivering the intervention in this study, and, so, the study was not blinded and was open, which could have introduced information bias and performance bias.

$\Rightarrow$ The anthropometric parameters at postintervention were not directly measured by the study team due to the COVID-19 pandemic and related social distancing rules.

\section{INTRODUCTION}

The Chinese physical activity guideline recommends that children aged 5-17 years should engage in at least 60 min of moderateto-vigorous physical activity (MVPA) per day and reduce their sedentary time. ${ }^{1}$ Physical activity improves children's overall health and can contribute to their social wellbeing. ${ }^{2}$ It can boost their learning abilities, including improvement in concentration power, memory, intellectual development and academic performance. ${ }^{2-4}$ However, around $84 \%$ of children in China do not meet the recommended physical activity levels, and this proportion is higher compared with that in many high-income Asian, European and American countries. ${ }^{5}$ The problem is more common among girls as there is a huge sociocultural pressure in the conservative Chinese society, and they are not allowed to do physical activities. ${ }^{5}$ MVPA starts to decline at around $10-12$ years of age.$^{6-9}$ For example, approximately $25 \%$ of children spend over $30 \mathrm{~min}$ on MVPA per day in primary school (for children aged $7-12$ years), whereas it is only $15 \%$ and 
$10 \%$ in junior middle schools (for children aged 13-15 years) and junior high schools (for children aged 16-18 years), respectively. ${ }^{6}$ In other words, it can be beneficial to target health behaviours (including physical activity) at this transition period as children approach adolescence. ${ }^{10}$

Yangzhou is an eastern city in China, located in the Jiangsu Province. Over half of the school-aged children are physically inactive in the Jiangsu Province, and their health and fitness are below the national average ${ }^{11}$ In this province, physical activity, health and fitness levels are the worst in Yangzhou city. ${ }^{12}$ In Yangzhou, less than $50 \%$ of children do physical activities for an hour per day, and the situation is even worse during the weekends when it comes down to only $14 \% .^{12}$

Targeting schools to promote children's physical activity appears to be promising. Children spend the majority of their waking hours in school, and, therefore, schools represent an ideal environment to reach them. ${ }^{13}$ Schools can provide access to children from different socioeconomic backgrounds and help institutionalise the physical activity interventions into other settings, such as communities. ${ }^{13}$ For instance, 5 to 45 min of MVPA per day can be achieved through school-based physical activity interventions. ${ }^{14}$ School-based physical activity interventions are relatively easy to implement and reasonably easy to evaluate. $^{15-17}$

The promotion of physical activity requires an understanding of the underlying influences on this behaviour. ${ }^{18}$ However, in China, previous physical activity interventions for children lacked a theoretical basis for targeting the potential drivers of this behaviour. ${ }^{19-21}$ We have addressed this issue, and our Joanna Briggs Institute qualitative systematic review on barriers and facilitators to physical activity among ethnic Chinese children has synthesised four broad themes, namely, personal, sociocultural, environmental and policy-related and program-related factors. ${ }^{22}{ }^{23}$ Based on these findings, we have developed a school-based behaviour change intervention to increase physical activity levels among children (aged 10-12 years) in China. ${ }^{24}$

From the evaluation point of view, the principal research question to be addressed by the cluster randomised controlled trial (RCT) in the future is whether the intervention is effective in increasing physical activity levels among children in China. The primary outcome of the future cluster RCT will be the difference in mean 7-day steps between the two study groups (ie, intervention and control). The chances of successful completion of a costly cluster RCT will improve if the feasibility of its key elements is checked before it starts. Thus, we determined the feasibility of undertaking the cluster RCT in the future and estimated important parameters that are needed to design this cluster RCT.

\section{METHODS}

\section{Study design}

This feasibility study was a cluster non-RCT. Cluster design (rather than individual allocation) was required to minimise contamination between intervention and control group participants due to the nature of the intervention.

\section{Study setting, participants and duration}

In China, the majority of children attend public schools. ${ }^{25}$ This study was conducted in two public schools in Yangzhou. The intervention was provided in one public school. Another public school in the city, matched on the basis of similar socioeconomic background of attending students, class size and curriculum structure, acted as the control. The distance between the two schools is around $15 \mathrm{~km}$, which minimised contamination. In these two schools, children aged 10-12 years (ie, from one class) with verbal assent and their parents with verbal consent were eligible, that is, child-parent dyads. The study information sheet and opt-out consent form were provided to parents through their children. Those who did not return the opt-out consent form signed by their parents were included in the study. Those with medical conditions or physical injuries that prevented them to engage in outdoor physical activities were excluded (as reported by their parents or teachers). The study duration was from May 2020 to October 2020.

\section{Sample size}

A formal sample size calculation is not usually required for a feasibility study. ${ }^{26} \mathrm{Sim}$ and Lewis have recommended recruiting at least 50 participants. ${ }^{27}$ Thus, we recruited a total of 64 children and their parents (32 per study group).

\section{Intervention}

A structured school-based behaviour change intervention was provided over 16 weeks to increase physical activity levels among children (aged 10-12 years). The intervention development paper will be published elsewhere. ${ }^{24}$ Briefly, this behaviour change intervention is based on the Behaviour Change Wheel and Theoretical Domains Framework. ${ }^{28}{ }^{29}$ It has three components: (a) health education (physical education), (b) family involvement and (c) school environment support. Health education for children was delivered face-toface, using presentation slides and printed materials including a physical activity diary. Family involvement was promoted through an online session and a physical activity booklet. Under school environmental support, sport equipment (eg, jumping rope, shuttlecock), a pedometer and a physical activity poster were provided to children. The content, structure and theoretical basis of each intervention component are detailed in online supplemental file 1 .

\section{Control}

No intervention was delivered in the control group, and children were requested to continue their usual physical activities. 
Table 1 Data collection

\begin{tabular}{|c|c|c|c|}
\hline & Assessment details* & Baseline & $\begin{array}{l}\text { At } 16 \text { weeks } \\
\text { (postintervention) }\end{array}$ \\
\hline Socio-demographics & & $\sqrt{ }$ & $\sqrt{ }$ \\
\hline Height & TZG (stadiometer) & $\sqrt{ }$ & $\sqrt{ }$ \\
\hline Weight & RGT-140 (weighing scale) & $\sqrt{ }$ & $\sqrt{ }$ \\
\hline Physical activity & $\begin{array}{l}\text { (a) Children's Leisure Activities Study } \\
\text { Survey }{ }^{48} \text {; time recall: past } 1 \text { week, (b) Yamax } \\
\text { SW-200 pedometer: 7-day steps }\end{array}$ & $\sqrt{ }$ & $\sqrt{ }$ \\
\hline $\begin{array}{l}\text { Self-efficacy (to assess confidence in } \\
\text { children's ability to do physical activities) }\end{array}$ & $\begin{array}{l}0-40 \text { rating scale; time-recall: at the time of } \\
\text { questionnaire completion }{ }^{49}\end{array}$ & $\sqrt{ }$ & $\sqrt{ }$ \\
\hline
\end{tabular}

${ }^{*}$ A standard operating procedure was developed for this purpose.

†Enjoyment scales are negatively worded and thus, higher scores indicate lower physical activity enjoyment.

\section{Study parameters and data collection}

- SD of the primary outcome (ie, 7-day steps in children) and intracluster correlation coefficient (ICC) were estimated and used to calculate the sample size of the future cluster RCT.

- Recruitment of child-parent dyads-number of them approached to participate, gave assent (children) and consent (parents), screened for eligibility and found eligible and recruited.

- Follow-up of children-number of them followed-up at 16 weeks (postintervention).

- Data collection completion among childrennumber of them completed the self-reported questionnaire, on whom anthropometric parameters were measured and provided the recording of 7-day steps at baseline and 16 weeks (postintervention) (see table 1).

- Time needed for data collection among children-time needed to complete the self-reported questionnaire by them and measure their anthropometric parameters at baseline and 16 weeks (postintervention).

- Intervention attendance-number of children and parents attended their respective group sessions.

\section{Adverse events}

The plan was to collect information on any adverse event (including death) occurring in children as a result of participation in the study and to involve two physical activity experts to determine the relationship between the intervention and adverse event.

\section{Withdrawal}

Children and their parents were made aware (through the information sheet) that their participation was entirely voluntary, and they could withdraw from the study at any time.

\section{Data analysis}

Data were summarised using summary measures of mean or median and spread (for continuous data) and numbers and percentages (for categorical data). This was a feasibility study and so was not adequately powered to detect a difference in outcomes between the two study groups. However, we calculated the initial estimates of effects to guide the design of the future cluster RCT. All primary analyses were based on the intention-to-treat principle and were unadjusted. Missing data were imputed using multiple imputations. Between the study groups, baseline and postintervention continuous data were compared using an independent t-test (for normally distributed data) or Mann-Whitney U-test (for skewed data). Categorical data were compared using the $\chi^{2}$ test. Within a study group, the change in an outcome from baseline to postintervention was compared using a paired t-test. As the study was not randomised, the adjustment was subsequently done for children's sex and the respective baseline value using multiple linear regression (in case of continuous data). The results were considered statistically significant when $p$ values were less than or equal to 0.05 . Statistical analysis was performed using Stata V.15 (StataCorp, Texas).

\section{Patient and public involvement}

Six lay people in China (intended user community) were involved when the intervention was developed. 


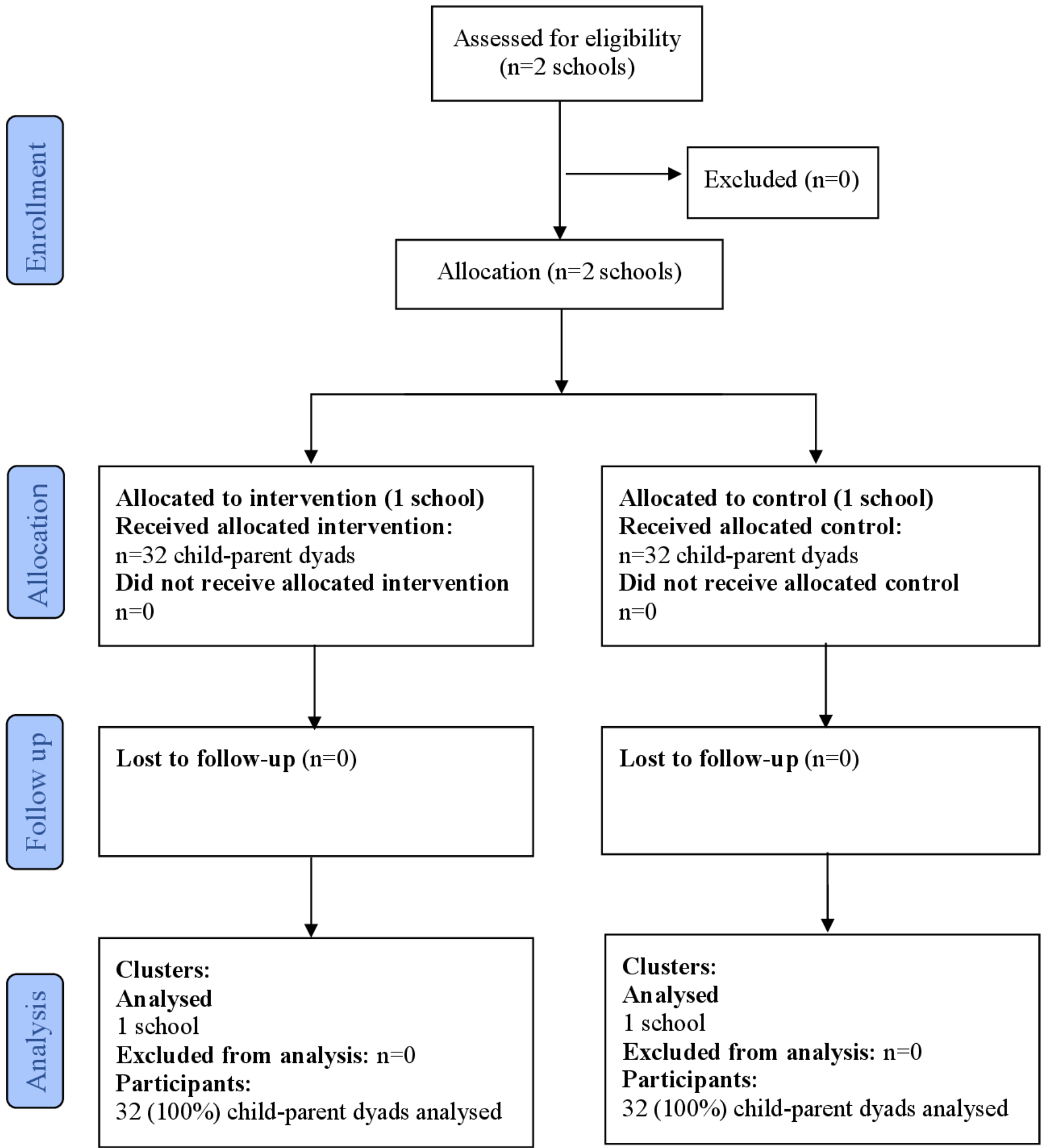

Figure 1 Flow diagram of study.

Specifically, the group included one boy and a girl aged 10-12 years, parents of each child (one father and one mother) and two physical education teachers (one man and one woman). The intervention materials were shared with them for feedback, that is, children reviewed the materials for the children, parents reviewed the materials for the children and parents and teachers reviewed all the materials. Apart from this, there was no other patient and public involvement in the study.

\section{RESULTS}

The results are reported in accordance with the relevant extension of the Consolidated Standards of Reporting 
Table 2 Estimation of parameters needed for designing the future cluster RCT

\begin{tabular}{|c|c|c|c|}
\hline & Total & Intervention & Control \\
\hline Child-parent dyads approached to participate & $64(100 \%)$ & $32(100 \%)$ & $32(100 \%)$ \\
\hline Children's parents gave consent & $64(100 \%)$ & $32(100 \%)$ & $32(100 \%)$ \\
\hline Child-parent dyads screened for eligibility & $64(100 \%)$ & $32(100 \%)$ & $32(100 \%)$ \\
\hline Follow-up of children at 16 weeks (postintervention) n (\%) & $64(100 \%)$ & $32(100 \%)$ & $32(100 \%)$ \\
\hline \multicolumn{4}{|l|}{ Data collection completion among children n (\%) } \\
\hline \multicolumn{4}{|l|}{ (a) Children completed the self-reported questionnaire } \\
\hline Baseline & $64(100 \%)$ & $32(100 \%)$ & $32(100 \%)$ \\
\hline 16 weeks (postintervention) & $64(100 \%)$ & $32(100 \%)$ & $32(100 \%)$ \\
\hline \multicolumn{4}{|l|}{ (c) Children provided the recording of 7 day steps } \\
\hline Baseline & $61(95.3 \%)$ & $31(96.9 \%)$ & $30(93.8 \%)$ \\
\hline 16 weeks (postintervention) & $64(100 \%)$ & $32(100 \%)$ & $32(100 \%)$ \\
\hline \multicolumn{4}{|l|}{ Time needed for data collection among children (mean minutes) } \\
\hline \multicolumn{4}{|c|}{ (a) Time needed to complete the self-reported questionnaire by children } \\
\hline Baseline & 30 & 15 & 15 \\
\hline 16 weeks (postintervention) & 30 & 15 & 15 \\
\hline \multicolumn{4}{|c|}{ (b) Time needed to measure anthropometric measurements in children } \\
\hline Group session 3 & $32(100 \%)$ & $32(100 \%)$ & $\mathrm{n} / \mathrm{a}$ \\
\hline Group session 4 & $32(100 \%)$ & $32(100 \%)$ & $\mathrm{n} / \mathrm{a}$ \\
\hline (b) Group session for parents & $32(100 \%)$ & $32(100 \%)$ & $\mathrm{n} / \mathrm{a}$ \\
\hline
\end{tabular}

$\mathrm{RCT}$, randomised controlled trial.

Trials statement and checklist (for pilot and feasibility trials) and flow diagram (for cluster trials; adapted). ${ }^{30-32}$ The study flow diagram is shown in figure 1 . Sixty-four children and their parents participated in the study (32 per study group).

\section{Estimation of parameters needed for designing the future cluster RCT}

Table 2 reports the estimation of parameters needed for designing the future cluster RCT.

Sample size calculation for the future cluster RCT

The SD of the primary outcome (ie, 7-day steps) was 34519 and ICC was 0.03 (previous Chinese studies have found similar smaller estimates) ${ }^{33-35}$ Using these estimates, a power of $80 \%$, a significance level of $5 \%$, an average class size of 32 children and assuming a $20 \%$ loss to follow-up at 16 weeks (postintervention), a sample size of 2000 participants recruited from 50 schools (ie, 1000 participants in 25 intervention schools and 1000 participants in 25 control schools) will be sufficient to determine a minimum clinically important difference of 7000 steps in the mean 7-day steps between the two study groups. ${ }^{3637}$

\section{Feasibility of undertaking the future cluster RCT}

The recruitment and follow-up rates were $100 \%$. The completion of data collection was 100\% (except for the 7-day steps at baseline-one child lost the step log in the intervention group and two children lost their 
Table 3 Baseline characteristics of participants

\begin{tabular}{|c|c|c|c|}
\hline & Intervention $(\mathrm{n}=32)$ & Control $(n=32)$ & $P$ value \\
\hline Children's age (years)* & $11.3 \pm 0.7$ & $11.3 \pm 0.6$ & 0.302 \\
\hline \multicolumn{4}{|l|}{ Children's sex $\mathrm{n}(\%)$} \\
\hline Female & $11(34.4 \%)$ & $17(53.1 \%)$ & 0.131 \\
\hline Male & $21(65.6 \%)$ & $15(46.9 \%)$ & \\
\hline \multicolumn{4}{|l|}{ Parents' education $\mathrm{n}(\%)$} \\
\hline \multicolumn{4}{|l|}{ Father } \\
\hline None & 0 & $1(3.1 \%)$ & 0.001 \\
\hline High school diploma or equivalent (0-12 years) & $17(53.1 \%)$ & $29(90.6 \%)$ & \\
\hline University or equivalent (>12 years) & $15(46.9 \%)$ & $2(6.3 \%)$ & \\
\hline \multicolumn{4}{|l|}{ Mother } \\
\hline None & 0 & $1(3.1 \%)$ & 0.002 \\
\hline High school diploma or equivalent (0-12 years) & $22(68.6 \%)$ & $31(96.9 \%)$ & \\
\hline University or equivalent (>12 years) & $10(31.4 \%)$ & 0 & \\
\hline \multicolumn{4}{|l|}{ Parents' employment n (\%) } \\
\hline \multicolumn{4}{|l|}{ Father } \\
\hline Employed & 31 (96.9\%) & $32(100 \%)$ & 0.313 \\
\hline Unemployed & $1(3.1 \%)$ & 0 & \\
\hline \multicolumn{4}{|l|}{ Mother } \\
\hline Employed & $29(90.6 \%)$ & $32(100 \%)$ & 0.076 \\
\hline Unemployed & $3(9.4 \%)$ & 0 & \\
\hline \multicolumn{4}{|l|}{ Physical activity } \\
\hline MVPA (minutes/week)* & $508.8(231.5,752.0)$ & $201(87.0,293.0)$ & $<0.001$ \\
\hline Seven-day steps ${ }^{\star}$ & $54989.0(35430.0,64805.0)$ & $67447.0(43667.0,90950.0)$ & 0.036 \\
\hline Height $(\mathrm{cm})^{\star}$ & $138.6 \pm 7.2$ & $137.1 \pm 7.1$ & 0.378 \\
\hline Weight $(\mathrm{kg})^{*}$ & $38.0 \pm 8.8$ & $36.2 \pm 6.2$ & 0.360 \\
\hline $\operatorname{BMl}\left(\mathrm{kg} / \mathrm{m}^{2}\right)^{\star}$ & $19.7 \pm 4.1$ & $19.3 \pm 3.1$ & 0.652 \\
\hline Waist circumference $(\mathrm{cm})^{*}$ & $69.2 \pm 10.7$ & $65.5 \pm 6.4$ & 0.101 \\
\hline Self-efficacy ${ }^{\star}$ & $33.0(27.5,37.5)$ & $26.0(22.0,30.0)$ & 0.001 \\
\hline Enjoyment* & $8.0(7.0,10.5)$ & $8.0(7.0,16.5)$ & 0.730 \\
\hline \multicolumn{4}{|l|}{ Social support* } \\
\hline Parents & $32.0(26.5,35)$ & $25.5(17.0,29.5)$ & 0.018 \\
\hline Friends & $26.0(14.0,34.0)$ & $22.5(15.0,31.0)$ & 0.455 \\
\hline
\end{tabular}

*Values are $\mathrm{n}(\%)$, mean \pm SD or median (IQR).

BMI, body mass index; MVPA, moderate-to-vigorous physical activity.

pedometer in the control group). The time needed to complete the self-reported questionnaire by children was around 15 min per study group, and the measurement of their anthropometric parameters took around $40 \mathrm{~min}$ per study group. The intervention attendance was $100 \%$.

\section{Baseline characteristics of participants}

The baseline characteristics of participants are presented in table 3. At baseline, both the study groups had similar characteristics except for parents' education, selfreported physical activity level, 7-day steps, self-efficacy and perceived social support from parents.

\section{Initial estimates of effects}

Tables 4 and 5 report the unadjusted and adjusted study outcomes, respectively. Compared with the control group, the 7-day steps were significantly lower in the intervention group (mean difference: -27742.3 ; 95\% CI -49112.6 to -6372.0 ) but had a higher self-efficacy (mean difference: 6.3; $95 \%$ CI 3.1 to 9.5 ). In the intervention group, body mass index (BMI) significantly reduced from the baseline to 16 weeks (mean difference: $-1.9 ; 95 \%$ CI -2.3 to -1.4 ) and self-efficacy significantly increased during this period (mean difference: 4.6 ; 95\% CI 2.4 to 6.8 ). After adjustment, similar results were found except for the BMI. 


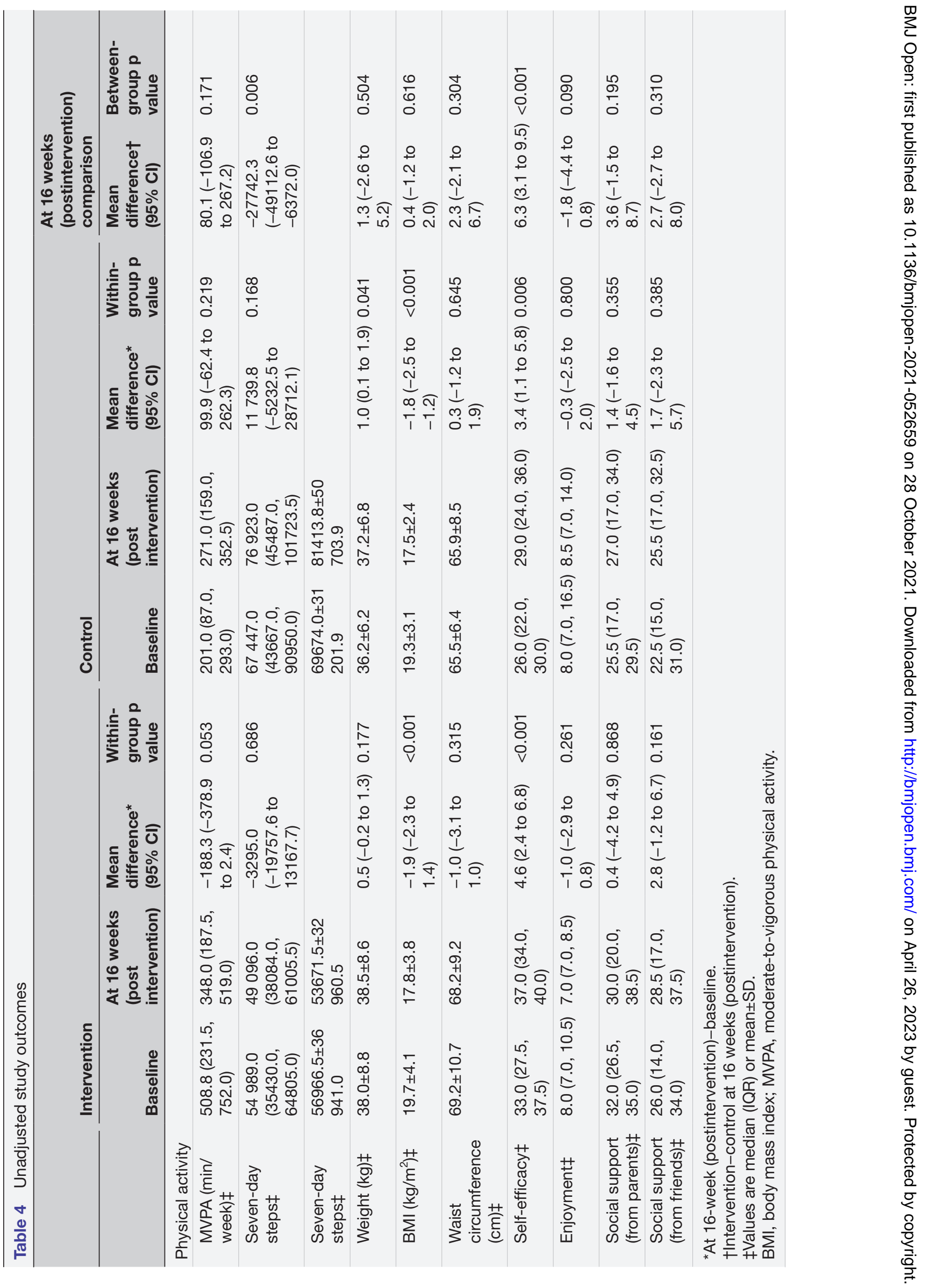




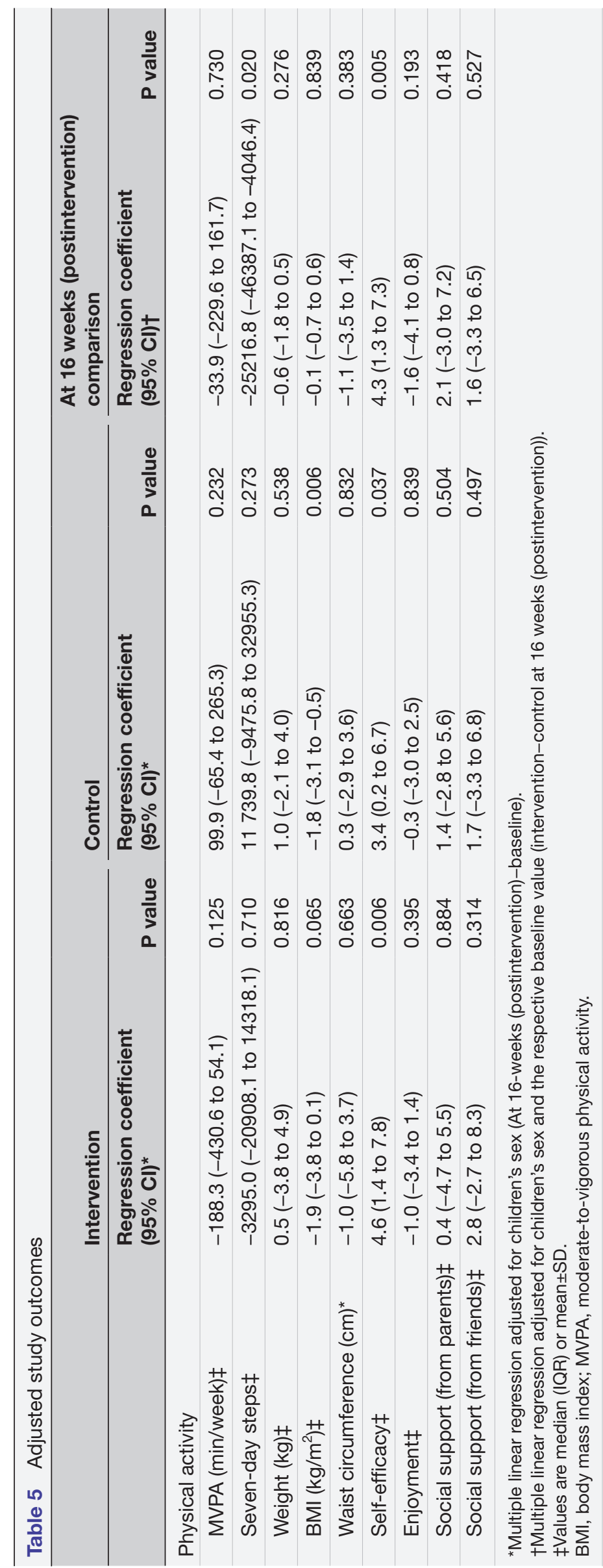




\section{Adverse events}

No adverse event was reported during the study.

\section{Withdrawal}

No one withdrew from the study.

\section{DISCUSSION}

In our study, the feasibility of undertaking the future cluster RCT was found to be promising even though the study was conducted during the COVID-19 pandemic. The recruitment, follow-up, completion of and time needed for data collection and intervention attendance were promising. In our study, the recruitment rate was high $(100 \%)$, similar to cluster RCTs conducted in China where the intervention targeted the physical activity levels of children in school settings $(91.2 \%$ and $96.5 \%) .{ }^{33} 38$ This indicates that schools are one of the best places to recruit child-parent dyads in China. Globally, similar schoolbased studies have reported lower recruitment rates. For example, the recruitment rates were $87.1 \%$ and $67.2 \%$ in studies conducted in the UK and Finland, respectively. ${ }^{39} 40$ Similarly, the follow-up rate was high $(100 \%)$ in our study, similar to the studies conducted in China $(96.4 \%$ and 93.7\%), UK (97\%) and Finland (86.5\%). ${ }^{33} 38-40$ The completion of data collection was $100 \%$ (except for the 7-day steps at baseline-one child lost the step log in the intervention group and two children lost their pedometer in the control group). In the future cluster RCT, we will use different strategies to minimise such losses, such as sending reminders and giving rewards. ${ }^{40}$ The intervention attendance was high $(100 \%)$ in our study, compared with children's attendance in studies conducted in the UK $(53 \%)$ and Finland $(70.4 \%) .{ }^{39} 40$

Although the 7-day steps did not increase in the intervention group compared with the control, the improvements were observed in children's BMI and self-efficacy, which could enhance children's motivation to take part in future physical activities. ${ }^{41-43}$ This decrease in BMI among children may be partly due to puberty, that is, growth in terms of height. ${ }^{445}$ It should be noted that this feasibility study was not adequately powered to detect a difference in outcomes between the two study groups, and the effectiveness of the intervention will be determined in the future cluster RCT. In the future cluster RCT, a leaflet containing information on physical activity will be provided to the participants in the control group.

If our school-based behaviour change intervention is found to be effective in the future cluster RCT, it could be scaled up in China and integrated into the health education curriculum through the involvement and engagement of key stakeholders. The intervention will increase the physical activity levels among children and their selfefficacy for physical activity participation. The long-term positive health, social and economic impact will be enormous. The promotion of one healthy behaviour can bring positive changes in another behaviour, for example, diet. The support needed from family and school to promote physical activity will improve. The schools and teachers (responsible for promoting physical activity) will get an evidence-based intervention to increase children's physical activity levels.

To the best of our knowledge, this was the first feasibility study of a physical activity intervention in Yangzhou. Although the baseline characteristics of the intervention and control group participants in this study were exceedingly different due to the non-randomised study design, the non-randomised study design has provided the estimates of many important parameters needed to design the future cluster RCT. A qualitative study (using semistructured interviews) was also conducted with a sample of children and their parents and teachers to explore their experiences in taking part in this intervention and study, which will be published separately. Decisions over whether to modify the intervention and study will mainly be informed by the qualitative data. The sample size was modest, although reasonable to address the aim of this feasibility study and was comparable with other feasibility studies of physical activity interventions targeting children. ${ }^{40} 46$ This study was not blinded and was open, and this could have introduced information bias and performance bias. Although it was difficult to blind participants and those delivering the intervention in this case, the plan is to blind the outcome assessors and data analysts in the future cluster RCT. In the future cluster RCT, there will be 25 schools (clusters) per study arm, and we will use multilevel models in the analysis that will address the clustered nature of the data. ${ }^{47}$ The follow-up was short in this study. We intend to do long-term ( $\geq 1$ year) follow-ups in the future cluster RCT. Due to the COVID-19 pandemic and related social distancing rules, the anthropometric parameters at postintervention were not directly measured by the study team. Instructions were provided by the study team over a video call, and anthropometric parameters were measured synchronously by the parents.

\section{CONCLUSIONS}

Based on the promising recruitment, follow-up, completion of and time needed for data collection and intervention attendance, it would be feasible to undertake the future cluster RCT in China.

\section{Author affiliations \\ ${ }^{1}$ Division of Epidemiology and Public Health, School of Medicine, University of Nottingham, Nottingham, UK \\ ${ }^{2}$ The Nottingham Centre for Evidence-Based Healthcare: A Joanna Briggs Institute Centre of Excellence, University of Nottingham, Nottingham, UK \\ ${ }^{3}$ School of Health Sciences, University of Nottingham, Nottingham, UK \\ ${ }^{4}$ NIHR Nottingham Biomedical Research Centre, University of Nottingham, Nottingham, UK}

\section{Twitter Holly Blake @hollyblakenotts}

Contributors HW took the lead in writing the manuscript. All authors provided critical feedback and helped shape the research, analysis and manuscript. HB and $\mathrm{KC}$ supervised the project. HW is responsible for the overall content as guarantor. 
Funding This study was funded internally by the University of Nottingham, UK (award number N/A). The funding agency had no role in conducting the study or writing the manuscript.

\section{Competing interests None declared.}

Patient consent for publication Consent obtained from parent(s)/guardian(s) Ethics approval Ethical approval was obtained from the Faculty of Medicine and Health Sciences Research Ethics Committee, University of Nottingham, UK (255-1902). Local approvals were obtained from the two local schools in Yangzhou, China. The study was registered with the Chinese Clinical Trials Registry (ChiCTR1900026865)

Provenance and peer review Not commissioned; externally peer reviewed.

Data availability statement Data are available upon reasonable request. Request for analyses of de-identified data from this trial should be directed to the corresponding author.

Supplemental material This content has been supplied by the author(s). It has not been vetted by BMJ Publishing Group Limited (BMJ) and may not have been peer-reviewed. Any opinions or recommendations discussed are solely those of the author(s) and are not endorsed by BMJ. BMJ disclaims all liability and responsibility arising from any reliance placed on the content. Where the content includes any translated material, BMJ does not warrant the accuracy and reliability of the translations (including but not limited to local regulations, clinical guidelines, terminology, drug names and drug dosages), and is not responsible for any error and/or omissions arising from translation and adaptation or otherwise.

Open access This is an open access article distributed in accordance with the Creative Commons Attribution Non Commercial (CC BY-NC 4.0) license, which permits others to distribute, remix, adapt, build upon this work non-commercially, and license their derivative works on different terms, provided the original work is properly cited, appropriate credit is given, any changes made indicated, and the use is non-commercial. See: http://creativecommons.org/licenses/by-nc/4.0/.

\section{ORCID iDs}

Haiquan Wang http://orcid.org/0000-0003-2874-766X

Kaushik Chattopadhyay http://orcid.org/0000-0002-3235-8168

\section{REFERENCES}

1 Zhang Y, Zhang Y, Ma S, et al. Physical activity guide for children and adolescents in China. Chin J Evid Based Pediatr 2017;12:401-9.

2 Strong WB, Malina RM, Blimkie CJR, et al. Evidence based physical activity for school-age youth. J Pediatr 2005;146:732-7.

3 Te Velde SJ, Lankhorst K, Zwinkels M, et al. Associations of sport participation with self-perception, exercise self-efficacy and quality of life among children and adolescents with a physical disability or chronic disease-a cross-sectional study. Sports Med Open 2018;4:38-48.

$4 \mathrm{Wu} \mathrm{XY,} \mathrm{Han} \mathrm{LH,} \mathrm{Zhang} \mathrm{JH,} \mathrm{et} \mathrm{al.} \mathrm{The} \mathrm{influence} \mathrm{of} \mathrm{physical} \mathrm{activity,}$ sedentary behavior on health-related quality of life among the general population of children and adolescents: a systematic review. PLoS One 2017;12:e0187668.

5 Guthold R, Stevens GA, Riley LM, et al. Global trends in insufficient physical activity among adolescents: a pooled analysis of 298 population-based surveys with 1.6 million participants. Lancet Child Adolesc Health 2020;4:23-35.

6 Zhang R, LI H. Associated factors of physical exercise participation among primary and middle school students in Jiangsu. Chinese Journal of School Health 2017:12:1793-5.

7 Zhu Z, Tang Y, Zhuang J, et al. Physical activity, screen viewing time, and overweight/obesity among Chinese children and adolescents: an update from the 2017 physical activity and fitness in China-the youth study. BMC Public Health 2019;19:197-204.

8 World Health Organization. Spotlight on adolescent health and wellbeing: findings from the 2017/2018 health behaviour in school-aged children (HBSC) survey in Europe and Canada, 2020. Available: http://www.hbsc.org/publications/international/

9 Scottish Office Department of Health. The Scottish health survey 2019, 2020. Available: https://www.gov.scot/publications/scottishhealth-survey-2019-volume-1-main-report/pages/3/

$10 \mathrm{He} \mathrm{L}$, Lin L. The tendency of the physical activity level among schoolaged urban children in China. Chinese Journal of School Health 2016;37:663-40.

11 Lu S, Li Z. Analysis of the influence of ecological factors on physical activity behaviour of urban adolescents in China: a case study of Jiangsu. Sports 2016;145:6-7.
$12 \mathrm{Li} \mathrm{L.} \mathrm{Investigation} \mathrm{and} \mathrm{analysis} \mathrm{of} \mathrm{sunshine} \mathrm{sports} \mathrm{in} \mathrm{secondary}$ schools in Yangzhou [Master thesis]. Yangzhou: University of Yangzhou, 2011.

13 Chen $\mathrm{Y}, \mathrm{Ma} \mathrm{L}, \mathrm{Ma} \mathrm{Y}$, et al. A national school-based health lifestyles interventions among Chinese children and adolescents against obesity: rationale, design and methodology of a randomized controlled trial in China. BMC Public Health 2015;15:210-9.

14 Dobbins M, DeCorby K, Robeson PH. School-Based physical activity programs for promoting physical activity and fitness in children and adolescents aged 6-18. Cochrane Database Syst Rev 2013;2:CD007651.

15 Owen KB, Parker PD, Van Zanden B, et al. Physical activity and school engagement in youth: a systematic review and meta-analysis. Educ Psychol 2016;51:129-45.

16 Watson A, Timperio A, Brown H, et al. Effect of classroom-based physical activity interventions on academic and physical activity outcomes: a systematic review and meta-analysis. Int J Behav Nutr Phys Act 2017;14:114-37.

17 Hills AP, Dengel DR, Lubans DR. Supporting public health priorities: recommendations for physical education and physical activity promotion in schools. Prog Cardiovasc Dis 2015;57:368-74.

18 Craig P, Dieppe P, Macintyre S, et al. Developing and evaluating complex interventions: the new medical Research Council guidance. Int J Nurs Stud 2013;50:587-92.

19 Feng L, Wei D-M, Lin S-T, et al. Systematic review and meta-analysis of school-based obesity interventions in mainland China. PLoS One 2017;12:e0184704.

20 Li Y-P, Hu X-Q, Schouten EG, et al. Report on childhood obesity in China (8): effects and sustainability of physical activity intervention on body composition of Chinese youth. Biomed Environ Sci 2010;23:180-7.

21 Liu A, Hu X, Ma G, et al. Evaluation of a classroom-based physical activity promoting programme. Obes Rev 2008;9 Suppl 1:130-4.

22 Wang $\mathrm{H}$, Blake $\mathrm{H}$, Chattopadhyay K. Barriers and facilitators to physical activity among ethnic Chinese children in school, home and community settings: a qualitative systematic review. JBI Evid Synth 2020;18:2445-11.

23 Wang $\mathrm{H}$, Blake $\mathrm{H}$, Chattopadhyay $\mathrm{K}$. Barriers and facilitators to physical activity among ethnic Chinese children: a systematic review protocol. JBI Database System Rev Implement Rep 2019;17:1-8.

24 Wang H, Blake H, Chattopadhyay K. Development of a school-based intervention to increase physical activity levels among Chinese children: a systematic iterative process based on behavior change wheel and theoretical domains framework. Front Public Health 2021;9:610245.

25 Meng X. An analysis of the course, mode and prospect of the development of private schools in China. Journal of Jianghan University 2004;21:97-100.

26 Thabane L, Ma J, Chu R, et al. A tutorial on pilot studies: the what, why and how. BMC Med Res Methodol 2010;10:1.

$27 \mathrm{Sim}$ J, Lewis M. The size of a pilot study for a clinical trial should be calculated in relation to considerations of precision and efficiency. $J$ Clin Epidemiol 2012;65:301-8.

28 Michie S, Atkins L, West R. The behaviour change wheel: a guide to designing interventions. Great Britain: Silverback Publishing, 2014.

29 Cane J, O'Connor D, Michie S. Validation of the theoretical domains framework for use in behaviour change and implementation research. Implement Sci 2012;7:37-53.

30 Eldridge SM, Chan CL, Campbell MJ, et al. Consort 2010 statement: extension to randomised pilot and feasibility trials. BMJ 2016;355:i5239.

31 Thabane L, Hopewell S, Lancaster GA. Methods and processes for development of a consort extension for reporting pilot randomised controlled trials. Pilot Feasibility Stud 2016;2:25.eCollection 2016.

32 Campbell MK, Piaggio G, Elbourne DR, et al. Consort 2010 statement: extension to cluster randomised trials. $B M J$ 2012;345:e5661.

33 Li B, Pallan M, Liu WJ, et al. The CHIRPY DRAGON intervention in preventing obesity in Chinese primary-school--aged children: $A$ cluster-randomised controlled trial. PLoS Med 2019;16:e1002971.

34 Xu F, Ware RS, Tse LA, et al. A school-based comprehensive lifestyle intervention among Chinese kids against obesity (CLICK-Obesity): rationale, design and methodology of a randomized controlled trial in Nanjing City, China. BMC Public Health 2012;12:316.

$35 \mathrm{Li} \mathrm{B}$, Adab P, Cheng KK. Family and neighborhood correlates of overweight and obesogenic behaviors among Chinese children. Int $J$ Behav Med 2014;21:700-9.

36 Duncan S, McPhee JC, Schluter PJ, et al. Efficacy of a compulsory homework programme for increasing physical activity and healthy eating in children: the healthy homework pilot study. Int $J$ Behav Nutr Phys Act 2011;8:127-10. 
37 Duncan S, Stewart T, McPhee J, et al. Efficacy of a compulsory homework programme for increasing physical activity and improving nutrition in children: a cluster randomised controlled trial. Int J Behav Nutr Phys Act 2019;16:1-12.

$38 \mathrm{Xu}$ F, Ware RS, Leslie E, et al. Effectiveness of a randomized controlled lifestyle intervention to prevent obesity among Chinese primary school students: CLICK-Obesity study. PLoS One 2015;10:e0141421.

39 Jago R, Sebire SJ, Davies B, et al. Randomised feasibility trial of a teaching assistant led extracurricular physical activity intervention for 9 to 11 year olds: action 3:30. Int J Behav Nutr Phys Act 2014;11:114.

40 Hankonen N, Heino MTJ, Hynynen S-T, et al. Randomised controlled feasibility study of a school-based multi-level intervention to increase physical activity and decrease sedentary behaviour among vocational school students. Int J Behav Nutr Phys Act 2017; $14: 37-50$.

41 Salmon J, Brown H, Hume C. Effects of strategies to promote children's physical activity on potential mediators. Int $\mathrm{J}$ Obes 2009;33:S66-73.

42 Dishman RK, Motl RW, Saunders R, et al. Enjoyment mediates effects of a school-based physical-activity intervention. Med Sci Sports Exerc 2005;37:478-87.
43 Mendonça G, Cheng LA, Mélo EN, et al. Physical activity and social support in adolescents: a systematic review. Health Educ Res 2014;29:822-39.

44 Vanderwall C, Randall Clark R, Eickhoff $\mathrm{J}$, et al. Bmi is a poor predictor of adiposity in young overweight and obese children. BMC Pediatr 2017;17:135.

45 Himes $\mathrm{JH}$. Challenges of accurately measuring and using BMl and other indicators of obesity in children. Pediatrics 2009;124 Suppl 1:s3-22.

46 Quirk H, Glazebrook C, Blake H. A physical activity intervention for children with type 1 diabetes- steps to active kids with diabetes (STAK-D): a feasibility study. BMC Pediatr 2018;18:37-48.

47 Kirkwood BR, Sterne JA. Essential medical statistics. 2nd edition. New Jersey: Blackwell publishing, 2003: 355-70.

$48 \mathrm{Li} \mathrm{H}$, Chen P, Zhuang J. Revision and reliability validity assessment of Children's leisure activities study survey. Chinese Journal of School Health 2011;32:268-70.

49 Liang Y, Lau PWC, Huang WYJ, et al. Validity and reliability of questionnaires measuring physical activity self-efficacy, enjoyment, social support among Hong Kong Chinese children. Prev Med Rep 2014;1:48-52. 